\title{
COMPUTER DESIGN OF LOW POWER N2O MONOPROPELLANT THRUSTER
}

\author{
G. N. Markelov
}

AOES Group BV, Noordwijk, the Netherlands (Gennady.Markelov@aoes.com)

\begin{abstract}
Development of computer model and preliminary design of the monopropellant (nitrous oxide) thruster that will be working under space vacuum conditions are presented in this paper. To perform such a design, two models have been developed, plug flow reactor and lumped thruster models. The plug flow reactor has been used to study conditions under which a thermal decomposition of nitrous oxide occurs. A range of initial temperature and pressure has been found that is used as initial guess for the thruster design. To perform a preliminary design of the thruster, the lumped model has been used. The model takes into account gas flow through the thruster, propellant decomposition, and heat exchange between thruster elements and gas and it is based on Zakirov's model. The novelty is that the current model does not need experimental data on combustion pressure as input parameter. The model has been applied to find a suitable design, for example, thruster size and working pressure for a given power range. Calculated time to achieve a steady state firing is in good agreement with available information on manufactured thrusters.
\end{abstract}

Keywords: nitrous oxide, plug flow reactor, lumped thruster mode, low power.

\section{INTRODUCTION}

Green technologies can help to reduce pollution and/or simplify work of personnel. For example, a replacement of hydrazine that is the most used propellant for space thrusters will simplify all procedures, for example, development and testing, loading of propellant etc. One of green propellants, nitrous oxide $\left(\mathrm{N}_{2} \mathrm{O}\right)$, has gained a lot of attention last decay. For example, thrusters based on the $\mathrm{N}_{2} \mathrm{O}$ have been developed in the UK [1], China [2, 3], Russia [4], USA [5], and Brazil [6]. This is because the $N_{2} O$ is non-corrosive, explosive proof, and can deliver performance that is comparable with thrusters based on hydrazine [1]. A thermal decomposition of the monopropellant starts at high temperatures and catalyst is applied to reduce the initial temperature. Catalyst has a limited range of working temperature and can degrade with time.

A number of $\mathrm{N}_{2} \mathrm{O}$ thrusters have been developed and most of them work under high combustion pressure, for example, 5 bar. Mass flow rate depends on available heating power, for example, the rate values are about 0.04 and $0.2 \mathrm{~g} / \mathrm{s}$ at the power input of about 30 [3] and up to $450 \mathrm{~W}$ [6], respectively. The latter provides a thrust of $0.2 \mathrm{~N}$. Ref. [4] presents $1 \mathrm{~N}$ thruster, however, there is no indication on applied power. It looks that the power is 
quite high to preheat the thruster up to $785^{\circ} \mathrm{C}$. This performance is in line with common liquid monopropellant thrusters that use hydrazine and deliver a thrust from $0.05 \mathrm{~N}$ [8] up to $445 \mathrm{~N}$ [9]. A computer model of the nitrous oxide thruster has been developed in [10] and it takes into account a mass flow rate through the thruster, propellant decomposition, and heat transfer between the thruster elements. The model has been improved in [11] to apply a more detailed chemistry model. This model uses experimental values of pressure and provides a very good prediction of temperature and mass flow rate.

A goal of this paper is a preliminary design of the monopropellant thruster that requires a low power [7] and does not use catalyst if it is possible. To perform such a design, two models have been developed, a plug flow reactor and the lumped thruster model. The first is used to study a thermal decomposition at different initial temperature, pressure, volume, and mass flow rate of the monopropellant through the reactor volume. The second model is applied to make a preliminary design of the thruster.

\section{PLUG FLOW REACTOR}

The plug flow reactor (PFR) models the chemical reactions taking place in gas flowing through a volume. The gas flow rate determines the time available for decomposition in the volume. For simulation purposes the volume is divided into volume elements, $d V$. It is assumed that in the volume element the gas is well mixed and the pressure change is negligible, that is, the pressure is constant. For these conditions the chemical reactions and the associated change of temperature are calculated. The result yields the input conditions for the next volume element. The dividing of the total volume into volume elements, $d V$, is equivalent to the dividing of the simulation time into time steps, $d t$. For constant pressure the temperature change is given by

$$
d T=\frac{P_{i n} / V-\sum_{i . j} H_{i} \frac{d n_{i, j}}{d t}}{\sum_{i} C_{p_{i}} n_{i}} d t
$$

where $P_{i n}$ is the power input, $H_{i}$ is the enthalpy of formation, $C_{p_{i}}$ is the specific heat for constant pressure. The term $\frac{d n_{i, j}}{d t}$ is the rate at which species $i$ (dis)appears in reaction $j$.

The following stable species can be formed with nitrogen and oxygen atoms: $N, N O$, $\mathrm{NO}_{2}, \mathrm{NO}_{3}, \mathrm{~N}_{3}, \mathrm{~N}_{3} \mathrm{O}, \mathrm{N}_{3} \mathrm{O}_{3}, \mathrm{~N}_{2} \mathrm{O}_{4}, \mathrm{~N}_{2} \mathrm{O}_{5}, \mathrm{~N}_{3}, \mathrm{O}, \mathrm{O}_{2}$, and $\mathrm{O}_{3}$. A literature study resulted in 134 possible chemical reactions for these species $[12,13,14]$. Simulations using all these reactions are CPU time consuming, therefore, a reduced set of reactions has been searched. First, all reactions with molecules containing more than two of the same atoms $\left(\mathrm{NO}_{3}, \mathrm{~N}_{2} \mathrm{O}_{3}\right.$, $\mathrm{N}_{2} \mathrm{O}_{4}, \mathrm{~N}_{2} \mathrm{O}_{5}, \mathrm{~N}_{3}, \mathrm{O}_{3}$ ) are removed which leaves 70 reactions. This is justified because species with many atoms only appear in very small quantities and therefore play a negligible role. Next the best reaction combination is determined 18 reactions. This set allows one to have good results in moderate temperature range (up to $2400 \mathrm{~K}$ ). For high values all reactions have to be considered to provide accurate results. Figure 1 shows a temperature change due to the thermal decomposition for three sets of reactions, 18, 70 and 134 reactions. All sets provide the same temperature increase up to $2800 \mathrm{~K}$ when almost all $\mathrm{N}_{2} \mathrm{O}$ is decomposed. Then temperature decreases and increases again for 18 reactions or it stays almost constant for 70 reactions and it decreases monotonically for 134 reactions. The latter is due to a formation of 
species that contain more than two of the same atoms. A difference in temperature can reach up to $400 \mathrm{~K}$. However, temperature in our computations with the thruster model has never exceeded $2400 \mathrm{~K}$.

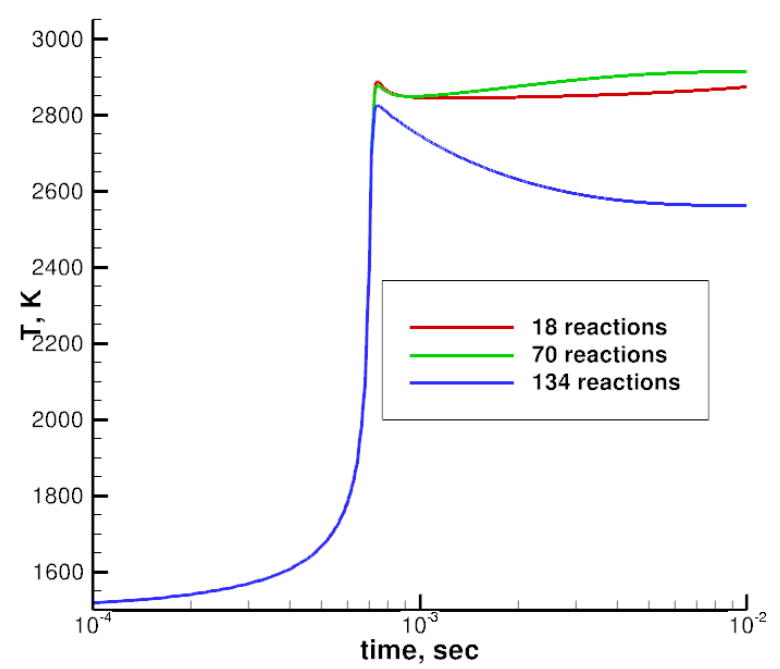

Figure 1. Effect of number of reactions (initial temperature of $1500 \mathrm{~K}$, pressure is $1 \mathrm{bar}$, mass flow rate is $0.1 \mathrm{~g} / \mathrm{s}$ )

\section{Lumped thruster model}

The propellant is injected in gaseous form into the combustion chamber where propellant can decomposes fully or partially depending on temperature, pressure, mass flow rate etc. When the temperature increases above a threshold, the decomposition process becomes self sustaining. There are practical restrictions on the temperature, the pressure and the combustion chamber volume attainable in the satellite engine. The goal of this study is to find the possible combinations of temperature, pressure and thruster size to allow the propellant decomposition.

A scheme of the thruster is shown in Fig. 2. In the middle of the chamber is a porous media, which is used as a base for catalyst. Casing is placed around it then the heater is. We consider that the heater is made of nichrome and resistojet can have a gas flow around the heater [17] that helps to reduce thruster wall temperature. However, nichrome experiences an oxidation under high-temperature decomposition products of nitrous oxide [4] and it is better to separate it from the gas flow. The thruster is wrapped with the thermal insulation to reduce a heat loss to the environment. The heat transfer to the satellite is ignored assuming that a connection is made with a proper thermal standoff (see, for example, [8]). The computer model is based on the following equations to compute heat conduction between the thruster elements and gas. The original model $[10,11]$ includes terms responsible for convection heat exchange between thruster and environment. They are omitted here because there is no air in space and most of the monopropellant systems are radiation cooled [17].

$$
C_{c} m_{c} \frac{d T_{c}}{d t}=\frac{T_{s}-T_{c}}{R_{c-s}}+h_{c} A_{c}\left(T_{g}-T_{c}\right)
$$




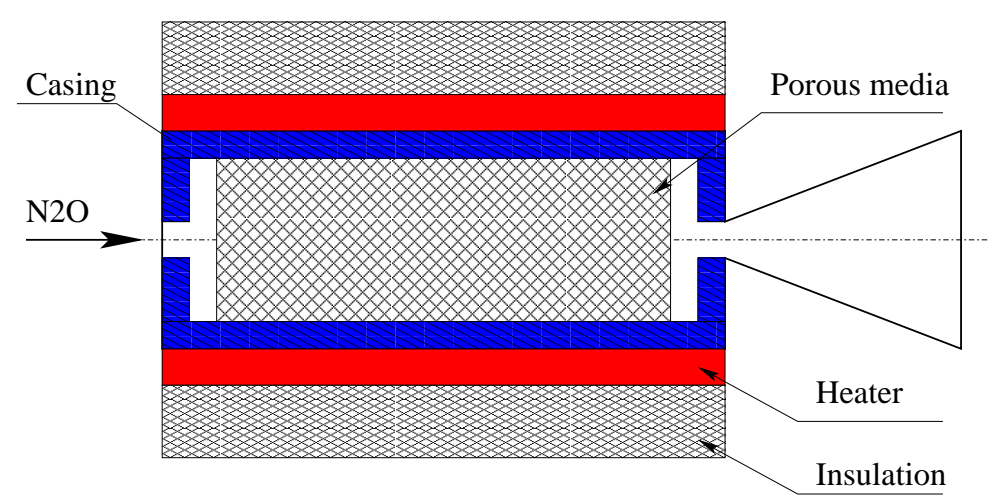

Figure 2. The standard thruster design

$$
\begin{gathered}
C_{s} m_{s} \frac{d T_{s}}{d t}=\frac{T_{h}-T_{s}}{R_{s-h}}-h_{s} A_{s}\left(T_{s}-T_{g}\right) \\
C_{h} m_{h} \frac{d T_{h}}{d t}=P_{i n}-\frac{T_{h}-T_{s}}{R_{s-h}}-\frac{T_{h}-T_{t i}}{R_{h-t i}} \\
C_{t i} m_{t i} \frac{d T_{t i}}{d t}=\frac{T_{h}-T_{t i}}{R_{h-t i}}-\epsilon \sigma A_{t i}\left(T_{t i}^{4}-T_{a m b}^{4}\right)
\end{gathered}
$$

where $m$ and $A$ are mass and surface area of the thruster element, subscripts are catalyst, $c$, gas, $g$, casing, $s$, heater, $h$, and insulation, $t i$. The thermal resistance, $R$, is calculated as [15]

$$
R_{1-2}=\frac{\frac{1}{\lambda_{1}} \ln \frac{r}{r_{1}}+\frac{1}{\lambda_{2}} \ln \frac{r_{2}}{r}}{2 \pi l},
$$

where $r_{1}$ and $r_{2}$ are 'gravity' center radii [11] for two adjoining hollow cylinders, $r$ is a radius of their contact surface, $l$ is the cylinder length, and $\lambda$ is thermal conductivity. Heat transfer coefficients, $h$, are calculated follow the formula in [11].

The propellant is supplied into the chamber using an injector. In real system the injector has few orifices, for example, 8 in [4]. For simplicity we assume only one orifice with a radius of $1 \mathrm{~mm}$ and discharge coefficient of unity. As a result of the finite orifice area a certain time is required to fill the combustion chamber. The gas leaves the thruster through the convergent-divergent nozzle and mass flow rate is estimated using 1D model and discharge coefficient is obtained using a Navier-Stokes solver. The main equation combines heat balance for gas and casing and catalyst

$$
\bar{H} \bar{\rho} V=H \rho V+\left(V W_{m}+A_{c} W_{t}\right) Q+\dot{m}_{i n j} H_{i n j}-\dot{m} \bar{H}-h_{c} A_{c}\left(T_{g}-T_{c}\right)+h_{s} A_{s}\left(T_{s}-T_{g}\right),
$$

where $\bar{H}$ and $\bar{\rho}$ are the specific enthalpy and density at the end of the time step. This equation is different from the correspondent equation in $[10,11]$ because there is no experimental value on pressure in our case. Reaction rates for homogeneous and heterogeneous decompositions of nitrous oxide are $[10,11]$

$$
\begin{gathered}
W_{m}=\rho_{N_{2} O} k_{m} \exp \left(-E_{a} / R T\right) \\
W_{t}=\rho_{N_{2} O} \sqrt{D_{N_{2} O} k_{t} \exp \left(-E_{a t} / R T\right)}
\end{gathered}
$$

Values of $E_{a}, k_{m}$, and $Q$ are taken from [10] and values of $k_{t}$ and $E_{a t}$ have been estimated applying the lumped model for experimental results on nitrous oxide catalytic decomposition [16]. Note that limited information is available on experimental results [16], 
therefore, it is impossible to establish an accuracy of the obtained values and its applicability to conditions different from those in Ref. [16]. Performing computations with the model, it has been found that Eq. 8 and detailed chemical kinetics produce different temperature of the decomposition products. Therefore, this equation has been replaced with 18 reactions and a part of the PFR model has been implemented in the lumped model. An application of 18 reactions increases required computational time drastically.

\section{Navier-Stokes modeling of the nozzle flow}

Navier-Stokes solver [18] has been used here to evaluated the performance of the nozzle. The nozzle throat area is $0.7776 \mathrm{~mm}^{2}$. This throat provides about $0.1 \mathrm{~g} / \mathrm{sec}$ mass flow rate for an ideal nozzle with chamber pressure of 1 bar and temperature of $1000 \mathrm{~K}$. The resulting throat radius is $0.49 \mathrm{~mm}$. The expansion area ratio for the considered nozzles is 200 and angle of the supersonic part is $15 \mathrm{deg}$.

Computations have been performed for chamber pressure of $1 \mathrm{~b}$ ar and range of chamber temperature from 300 up to $3000 \mathrm{~K}$ and adiabatic wall. The flow is assumed laminar. The solver uses only one species; therefore, the working gas is air, which is close to mixture of nitrogen and oxygen generated due to nitrous oxide decomposition. The computational mesh are 100x60 and 200x90 cells and cells were clustered to the throat and walls to increase flow resolution in these areas of strong flow gradients. Both meshes provide very similar results, therefore, the results are mesh-converged. Figure 3 shows Mach number flow field. The nozzle flow is characterized with a thick boundary layer and maximum value of Mach number at the exit of the standard nozzle reaches 5.5.

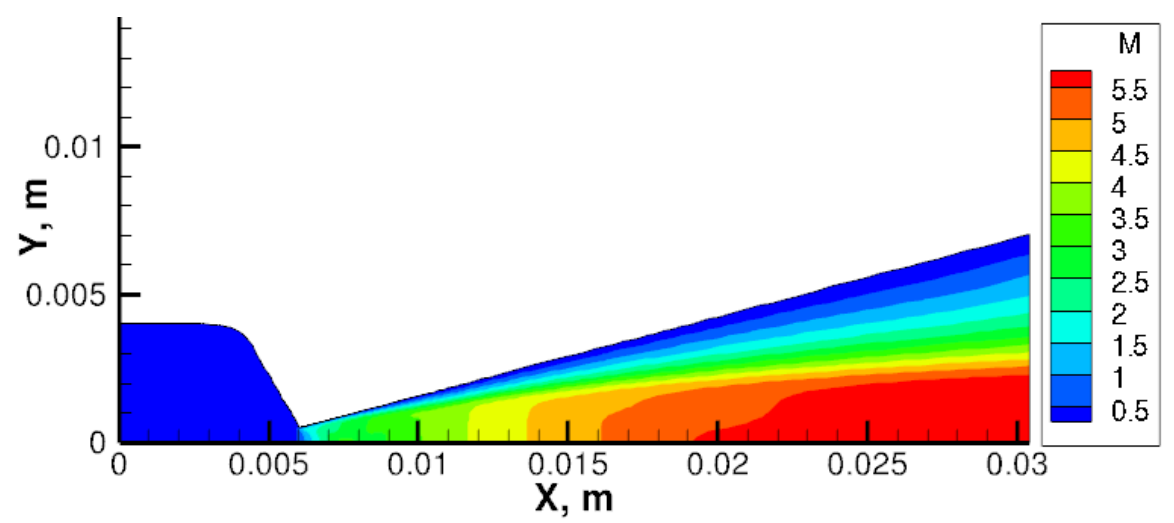

Figure 3. Mach number flow field for standard nozzle (chamber temperature of $1000 \mathrm{~K}$ )

The calculated nozzle performance is given in Table 1. The thrust decreases with chamber temperature due to growth of boundary layer thickness. A discharge coefficient, ratio of mass flow rate to the $1 \mathrm{D}$ isoentropic value, is almost constant. The value is used for the lumped thruster model to calculate a mass flow rate. An increase of the chamber pressure slightly affects the discharge coefficient value.

\section{Lumped thruster model results}

Simulations have been performed for the different parameters. The main set of the parameters is the following. 


\begin{tabular}{llll}
\hline $\mathrm{T}, \mathrm{K}$ & thrust, $\mathrm{N}$ & $I_{s p}, \mathrm{sec}$ & $C_{D}$ \\
\hline 300 & 0.127 & 75.4 & 0.951 \\
600 & 0.125 & 104.5 & 0.950 \\
800 & 0.123 & 119.3 & 0.949 \\
1000 & 0.122 & 132.1 & 0.948 \\
1200 & 0.120 & 143.0 & 0.948 \\
1600 & 0.117 & 161.3 & 0.947 \\
2400 & 0.114 & 192.2 & 0.944 \\
\hline
\end{tabular}

Table 1. Nozzle performance

- Combustion chamber length is $0.1 \mathrm{~m}$.

- The combustion chamber volume is 0.1 liter.

- An input power is $50 \mathrm{~W}$.

- Temperature and pressure of injected $\mathrm{N}_{2} \mathrm{O}$ are $300 \mathrm{~K}$ and 1 bar, respectively.

- Thermal insulation is a thing foil with a low emissivity of $0.08,0.09$, and 0.1 .

- Stainless steal is applied for casing $[3,4]$ and thermal insulation, thickness of 0.5 and $0.1 \mathrm{~mm}$, respectively.

- Porous media is aluminum [3] and it fills entire combustion chamber.

- Heater is nichrome with $0.25 \mathrm{~mm}$ thickness.

Computations have been done for the preheated thruster. Initially, the empty thruster has been heated and when casing temperature reaches a given value, the propellant injection starts. Gas and wall temperatures are about $1250 \mathrm{~K}$ that is lower by about $100 \mathrm{~K}$ than correspondent values in [4]. This difference is small and it can serve as a validation of the developed model. A higher initial temperature leads to faster decomposition and decreases time to get a steady state firing. Nevertheless, even in the case of $700 \mathrm{~K}$, the steady state is reached in $800 \mathrm{sec}$. This time is comparable with operations of Surrey-3 and NOMP-1 thrusters [2]. Only miniaturization of the thruster allowed authors [2] to decrease the start-up time down to $50 \mathrm{sec}$. Based on the obtained results a relative large low-power thruster can be used only as a long firing thruster to use propellant effectively. Steady state temperature is about $1200 \mathrm{~K}$ that is OK for high-temperature stainless steel but the catalyst and aluminum porous media can melt and blow away. Pressure in the combustion chamber can overshoot 1 bar in performed computations, insignificantly. An increase of the throat radius leads to higher initial heating of the gas because heat transfer coefficient depends on Reynolds number. However, a supply of cold propellant leads to smaller maximum temperature and extinguishes the decomposition. A decrease of the throat radius leads to a smaller mass flow rate and lower working temperature due to lack of the fresh propellant. For example, the chamber temperature has decreased by $200 \mathrm{~K}$ when the throat radius is decreased by a factor of 2 . A variation of the throat area can control working temperature inside the combustion chamber and heating of the thruster walls. 


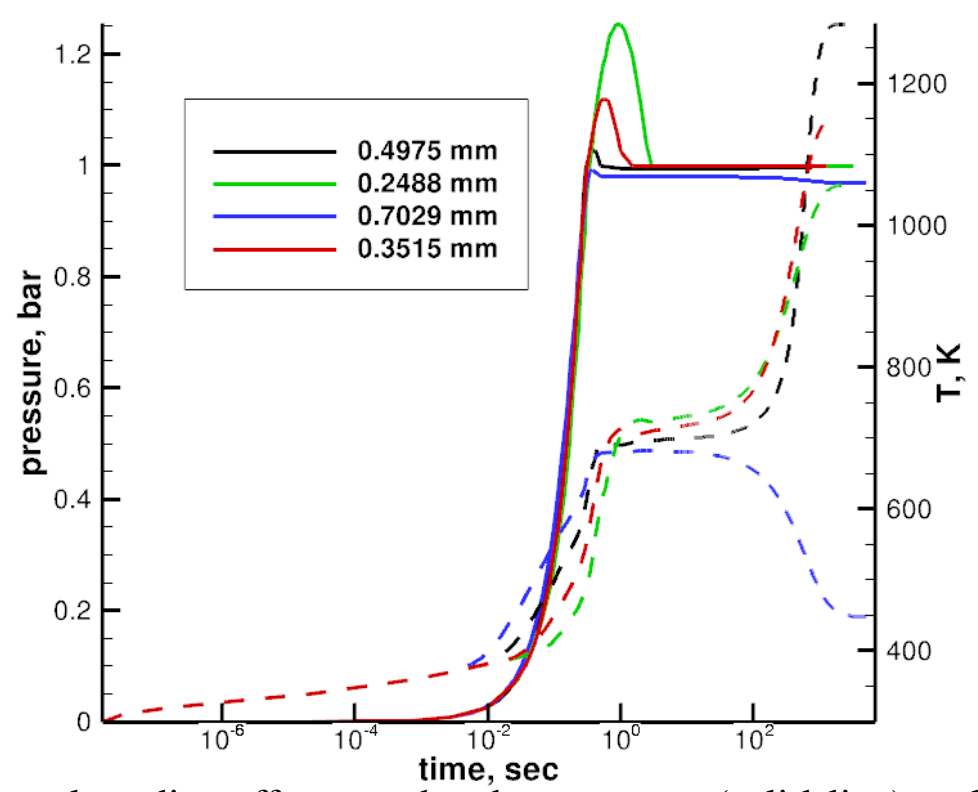

Figure 4. The nozzle radius effect on chamber pressure (solid line) and gas temperature (dashed line) (initial temperature of $700 \mathrm{~K}$, with catalyst)

To preheat the thruster up to higher temperature and to have propellant decomposition without catalyst, it is required to decrease radiation loses. Obviously, a decrease of emissivity and radiative surface area, for example, due to thruster length and volume (or radius) leads to a higher thruster temperature. A computation with temperature of $1108 \mathrm{~K}$ (the highest in the Table 2) does not lead to self-sustaining decomposition. Fig. 5 shows density of $\mathrm{N}_{2} \mathrm{O}, \mathrm{N}_{2}$, and $\mathrm{O}_{2}$ and gas and casing temperatures. Gas temperature almost reaches the thruster elements temperature and decompositions starts. However, a constant supply of fresh propellant with temperature of $300 \mathrm{~K}$ stops the decomposition. In addition, the following activities have been conducted but they did not help to obtain the self-sustaining decomposition

- increase of casing thickness up to $2 \mathrm{~mm}$ to increase the thruster mass and heat capacity,

- changing of injector cross-section area to change velocity of building pressure inside the combustion chamber,

- chamber pressure increase.

The injector radius affects a time of the chamber filling. A larger radius leads to faster filling and pressure overshoot increases due to heating. The pressure increase helps to start the propellant decomposition but not to create a self-sustaining decomposition and pressure comes back to the prescribed value of 1 bar. An increase of pressure chamber leads to a higher mass flow rate through the thruster that extinguishes the initial ignition under considered conditions. The propellant has been injected only when a chamber pressure is not higher than an injection pressure. When a propellant supply is stopped, the propellant in the combustion chamber decomposes and someone may say that a small supply of the propellant can help to keep the decomposition and, as a result, lead to self-sustaining decomposition. Additional computations have been done using a smaller injector and propellant has been injected in the chamber using higher pressure. In this case there is no stop of the propellant supply; however, this does 
not help to obtain the self-sustaining decomposition. Clearly, there is a need to reduce the throat area for higher pressure that will decrease thrust and specific impulse.

\begin{tabular}{llll}
\hline$\epsilon$ & $V, l$ & $l, \mathrm{~m}$ & $T$ \\
\hline 0.1 & 1 & 0.1 & 703.6 \\
0.1 & 0.5 & 0.05 & 836.8 \\
0.1 & 0.3 & 0.03 & 950.7 \\
0.09 & 1 & 0.1 & 722.4 \\
0.08 & 1 & 0.1 & 744.0 \\
0.08 & 0.1 & 0.05 & 1077 \\
0.08 & 0.1 & 0.04 & 1108 \\
0.08 & 0.2 & 0.04 & 1019 \\
0.08 & 0.4 & 0.04 & 935.5 \\
0.08 & 0.8 & 0.04 & 858.6 \\
\hline
\end{tabular}

Table 2. Steady state temperatures as function of the thruster volume and length for different emissivity

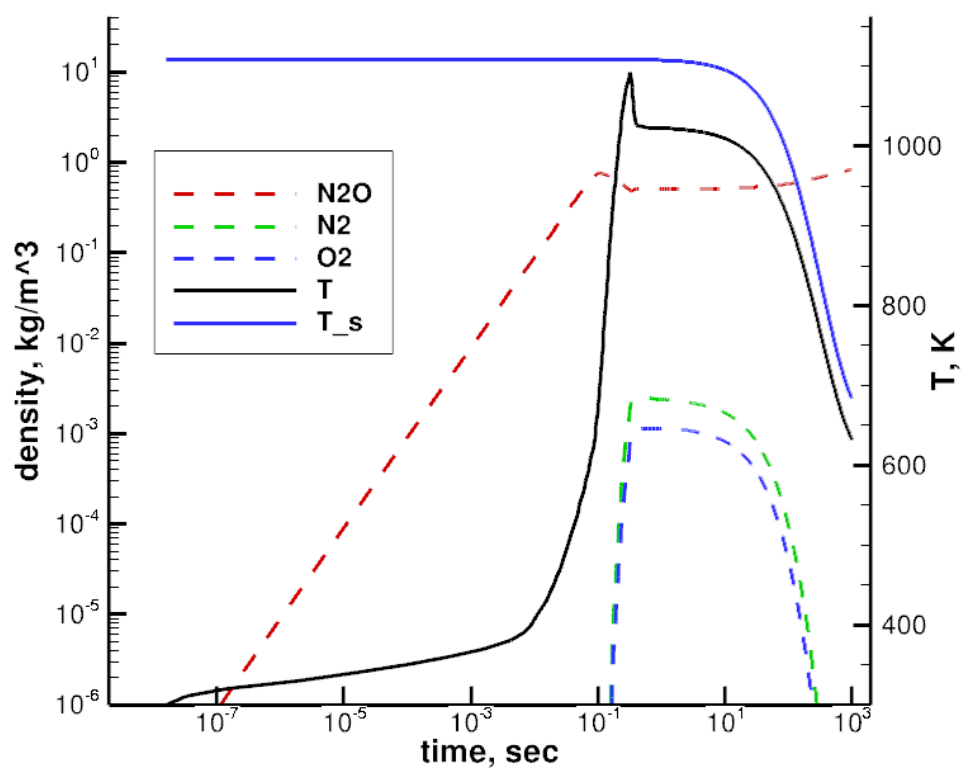

Figure 5. Preheated thruster firing without catalyst $(\epsilon=0.08, V=0.1 l, l=0.04 \mathrm{~m}$ )

It has been found that the only way to have the self-sustaining decomposition is to increase the input power. An increase of power, $60 \mathrm{~W}$, leads to stronger decomposition but it is not strong enough to create a self-sustaining decomposition. Further increase of the power leads to a very strong decomposition when almost all $\mathrm{N}_{2} \mathrm{O}$ decomposes and gas temperature reaches $2500 \mathrm{~K}$ (Fig. 6). In this case, pressure overshoots the prescribed value, 1 bar, by a factor of 3 and a propellant supply is switched off until the chamber pressure drops down to 1 bar. The gas temperature drops as well then it increases again. The steady state temperature is lower than a thermodynamic value, about $1900 \mathrm{~K}$ [2]. This is due to heat loss inherent for a realistic thruster model.

A use of 2 bar combustion pressure leads to self-sustaining decomposition for the given thruster geometry and input power of $60 \mathrm{~W}$ (Fig. 7). It is interesting to note that the 


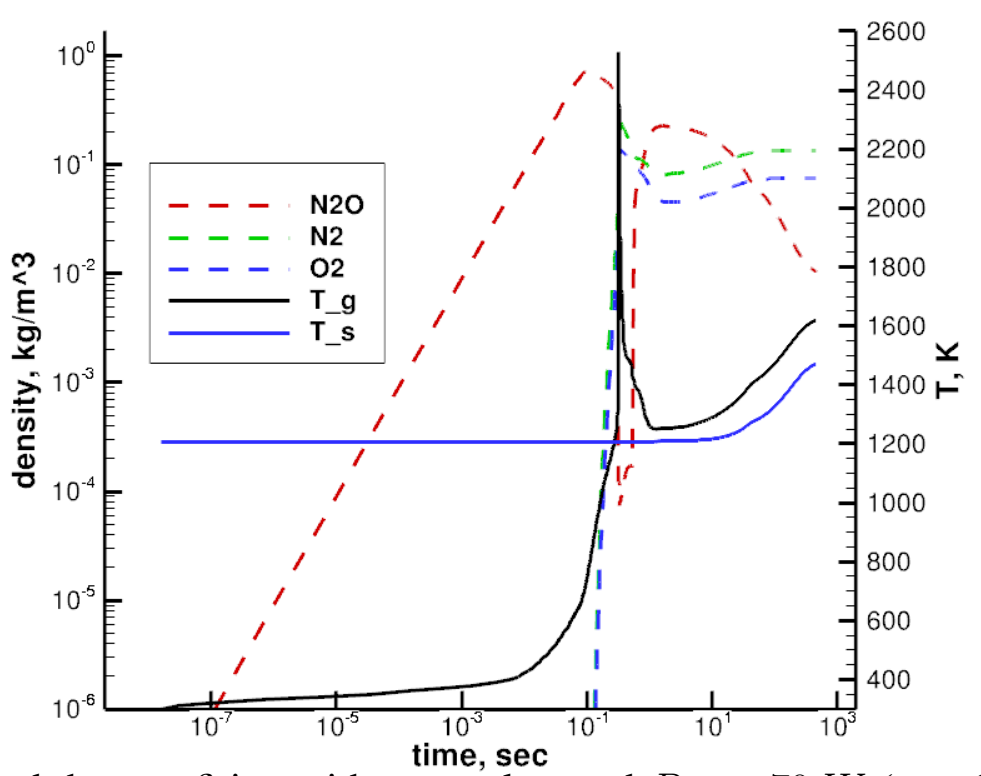

Figure 6. Preheated thruster firing without catalyst and $P_{\text {in }}=70 \mathrm{~W}(\epsilon=0.08, \mathrm{~V}=0.1 \mathrm{l}$, $l=0.04 \mathrm{~m})$

injector radius becomes important. A decrease of the radius leads to longer time of building pressure inside the combustion chamber and even higher combustion pressure, 5 bar, can not create a self-sustaining decomposition. For small injector cross-section area it is required to reduce the nozzle throat to get the self-sustaining decomposition. For example, only a reduction of throat height by a factor of 2 allowed to have the decomposition at 10 bar and injector radius of $0.3 \mathrm{~mm}$.

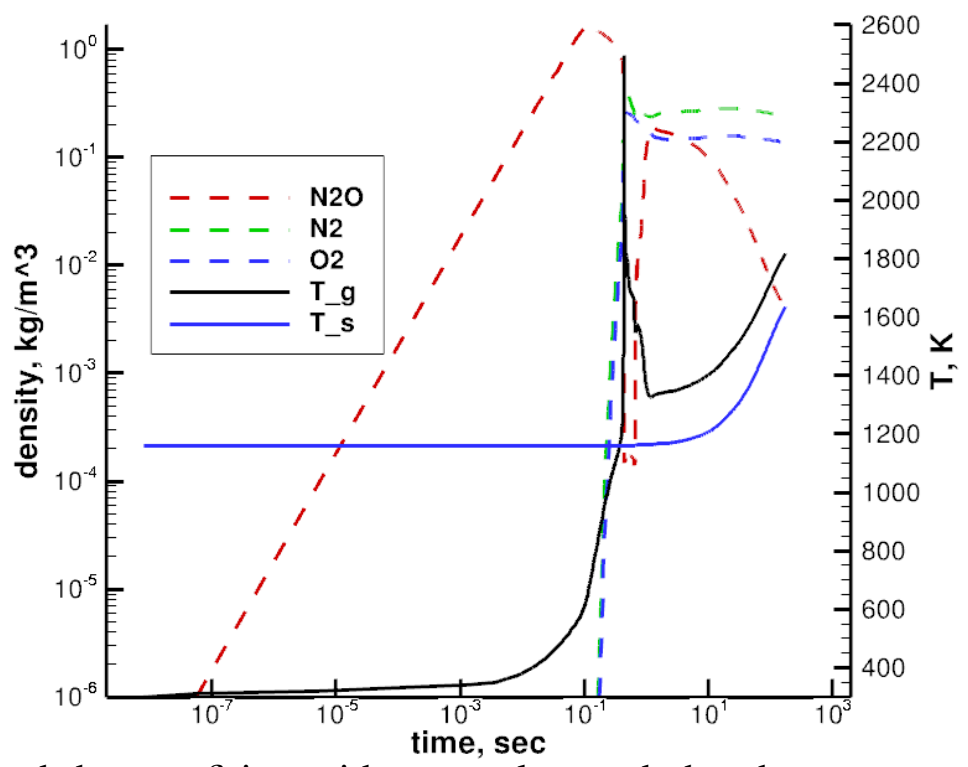

Figure 7. Preheated thruster firing without catalyst and chamber pressure of 2 bar $\left(P_{\text {in }}=\right.$ $60 \mathrm{~W}, \epsilon=0.08, V=0.1 l, l=0.04 \mathrm{~m}$ ) 


\section{Conclusions}

Two computer models have been developed, plug flow reactor and lumped thruster model. The plug flow reactor has been used to study conditions under which a self-sustaining thermal decomposition of nitrous oxide occurs and to find a reduced set of chemical reactions.

A goal of the lumped thruster model is to perform a preliminary design of thruster. The model takes into account gas flow through the thruster, propellant decomposition, and heat exchange between thruster elements and gas and it is based on the model published in $[10,11]$. The difference is that the current model does not need measurements of the combustion pressure versus time as input for the model.

The cold start of thruster can lead to the propellant decomposition using the catalyst. However, it will take a lot of time and it is more efficient to preheat the thruster as it is done for real thrusters $[2,3,4,6]$. The preheating allows one to get faster a steady state firing.

The radiative loss does not allow one to develop the thruster without catalyst. A drastic decrease of thruster size helps to reduce the loss. A decrease of the thruster size is still not enough to have the self-sustaining decomposition without catalyst. Only increase of the input power up to $70 \mathrm{~W}$ allows one to ignite the propellant and have self-sustaining decomposition. An increase of combustion chamber pressure can decrease a required input power and selfsustaining decomposition has been obtained using input power of $60 \mathrm{~W}$ at chamber pressure of 2 .

\section{Acknowledgements}

This work has been supported by the 7th Framework Program of the EU in the frame of the research program Helicon Plasma hydrazine combined micro (the project number is 218867). The author is thankful to Dagmar de Roij for coding the plug flow reactor model and search a reduced set of reactions.

\section{References}

[1] Zakirov V.A. "Investigation into nitrous oxide propulsion option for small satellite applications”, Ph.D. thesis, University of Surrey, 2001.

[2] Zakirov V.A., Li L., and Ke G. "N2O propulsion research at Tsingua: 2003”, Proc. 2nd Int. Conf. on Green Propellants for Space Propulsion, SP-557, 2004.

[3] Zakirov V.A., Wang K., Tang C., Shan F., Zhang H., and Li L. "N2O propulsion research at Tsingua: 2006", Proc. 3rd Int. Conf. on Green Propellants for Space Propulsion, SP$635,2006$.

[4] Sadov V., Yaroshenko N., Gaydey T., Filatov S., Kokorin A., Pillet N. "Performance of 1N model thruster on nitrous oxide", Proc. 3rd Int. Conf. of Green Propellants for Space Propulsion, SP-635, 2006.

[5] Lohner K., Dyer J., Doran E., Dunn Z., Krieger B., Decker V., Wooley E., Sadhwani A., Cantwell B., and Kenny T. AIAA Paper 2007-5463, 2007. 
[6] Costa F.S., Albuquerque-Jr J., and Soares-Neto T.G. "Initial development of a N2O electrothermal catalytic thruster", Proc. Space Propulsion Conference, 2010.

[7] Pavarin D., Ferri F., Manente M. Curreli D., Guclu Y., Melazzi D., Rondini D., Suman S., Carlsson J., Bramanti C., Ahedo E., Lancellotti V., Katsonis K. Markelov G. "Design of $50 \mathrm{~W}$ helicon plasma thruster", IEPC Paper 2009-205, 2009.

[8] Space mission analysis and design, eds. Wertz J.R. and Larson W.J., third edition, Kluver, 1999.

[9] http://www.ampacisp.com/products 2.php

[10] Zakirov V.A. and Zhang H. "Model for N2O monopropellant thruster operation", Proc. of IMechE, part G: J. Aerospace Engineering, 222, 2008, pp. 103-108.

[11] Zakirov V.A., Zhang H., and Li J. "The progress in simulation of nitrous oxide monopropellant operation”, EUCASS Paper 2009-287, 2009

[12] Gupta R.N., Yos J.M., Thompson R.A., Lee K.-P. “A review of reaction rates and thermodynamic and transport properties for an 11-species air model for chemical and thermal nonequilibrium calculations to 30000 K”, NASA Reference Publications, 1990.

[13] National Institute of Standards and Technology, NIST Chemical Kinetics Database, http://kinetics.nist.gov/kinetics/

[14] Chernyi G.G., Losev S.A., Macharet S.O., Potapkin B.V. "Physical and chemical processes in gas dynamics: physical and chemical kinetics and thermodynamics of gases and plasmas", Volume II, AIAA Inc., 2004.

[15] Heat transfer handbook, eds. Bejan A. and Kraus A.D., John Willey \& Sons, 2003.

[16] Zakirov V. "Catalytic decomposition of nitrous oxide for spacecraft application (Phase 1)", SSTL report SPAB-17101-01, 2001.

[17] Humble R.W., Henry G.N., Larson W.J. "Space propulsion analysis and design”, Space technology series, McGraw-Hill, 1995.

[18] Wong H., Schwane R. "Numerical investigation of transition in flow separation in a dual-bell nozzle", Proc. 4th European Symposium on Aerothermodynamics for Space Vehicles, Edited by R. A. Harris, ESA SP-487, p.425, 2002. 